\title{
학술지 논문의 질 관리와 논문의 철회
}

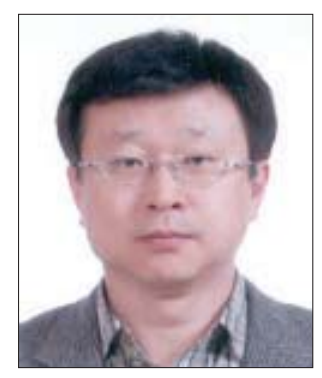

글 황은성

서울시립대 생명과학과 교수 과편협 출판윤리위원장

\begin{abstract}
저널에 수록된 논문의 질적 수준을 높이면서도 연구 진실성도 확보하는 일은 편집 자의 주요한 과제라고 할 수 있다. 영국에서 일어난 사례를 통해 이 같은 고민을 살펴 볼 수 있는 지면을 마련한다. 이 글은 『과편협 뉴스레터』1호에 실었던 내용을 바탕으 로 다시 작성한 것이다.
\end{abstract}

\section{학술지의 연구진실성 확보}

근래 오픈 액세스(open access) 저널들의 폭발적인 증가는 과학 커뮤니티는 물론 일반인들도 학술논문을 쉽게 접할 수 있게 하므로 연구결과의 신속한 지식화와 실용화를 크게 도모할 것으로 기대된다. 그러나, 그 이 면에는 부실한 논문의 양산(量産)이라는 무시하지 못할 부작용도 내재하고 있다. 질이 낮은 논문의 양산 자체도 문제지만, 급증하는 투고논문에 대한 상호 심의(peer review)의 하중(load)이 학계 전체에 부담으로 작용하 면서 충실한 논문심사가 일어나지 못하는 문제는 이미 여러 국제저널들에서 발생하고 있는 듯하다.

편집자가 투고된 논문을 대강 읽으면서 보면서 연구
부정이 개입되어 있는지를 판단하기는 쉽지 않다. 특히, 현재의 시스템으로는 저자가 맘먹고 데이터의 날조와 변조를 하고자 하면 편집자나 논문심사위원이 리뷰단계 에서 이를 솎아 내는 것은 거의 불가능하다. 그럼에도 이런 논문의 게재를 가능한 한 줄여서 학술지의 연구진 실성을 확보하는 것은 편집인의 몫이다. 그리고 이미 게재가 된 논문에서 데이터의 날조와 변조가 드러났을 때, 신속하고 적절한 조치를 취하는 것도 그에 못지않게 중요한 일이다. 특히, 표절과 달리 데이터 날조와 변조 는 잘못된 정보를 제공하여 다른 사람의 연구 역시 헛되 게 만드는 등 직접적인 폐해가 매우 크기 때문에 이의 후속처리가 신속하게 이루어져야 한다. 


\section{영향력 지수와 논문의 철회비율}

2009년 영어, 이탈리아어, 프랑스어, 스페인어권 논 문들을 대상으로 메타분석을 하여 보고한 Fanelli에 의 하면 2퍼센트의 과학자들이 스스로 중대한 연구부정 행위(표절은 포함되지 않았음)를 한 번 이상 했고, 14 퍼 센트가 동료의 데이터변조 행위를, 72 퍼센트가 동료의 다른 유형의 연구부정 행위를 알고 있음을 인정하였다 고 한다.[1] 발표되는 논문들의 이면에는 생각보다 많 은 연구부정이 개입되고 있음을 짐작하게 한다. 논문의 철회(retraction)도 이러한 현상에 비례하여 늘어나는 것 같다. 2011년 Steen이 보고한 바에 따르면 최근 10 년 사이에 철회된 논문의 수는 그 전 10 년간의 건수 대 비 10 배로 증가하였고, 그 원인 중 많은 것이 연구부정 으로 기울어져 있다.[2] 즉, 점차 많은 논문에서 의도적 인 부정이 개입되고 있다는 것이다.

철회와 관련하여 또 한 가지 흥미로운 보고가 있는 데, Infection and Immunity (IAI) 2011년 10월호에 실린 "Retracted Science and the Retraction Index"라는 editorial(논평) ${ }^{3}$ 에서는 저널의 impact factor와 철회비율과의 비례관계를 애기하고 있다. [3]. Impact factor가 2.0(Microbial Pathogenesis) 에서 53.484(New England J of Medicine)에 이르는 17개의 Pubmed 저널들에서의 2001 2010년 사이의 철회율(철회된 논문 수 / 게재된 논문 수)을 조사한 결 과, $\mathrm{P}<0.0001$ (Spearman rank correlation)의 유의 성으로 impact factor와 철회율 간에는 일직선의 비례 관계가 존재하는 것으로 나타났다. Impact factor가 큰 저널에 게재된 논문들이 낮은 저널에 게재된 논문들 보다 철회될 확률이 높다는 것이다. 이것은 소위 $\mathrm{CNS}$
라 불리는 높은 임팩트 저널의 논문들이 부정하게 만들 어진 것을 의미하는 것이 아니라, 보다 많은 연구자들 이 이들 저널에 게재된 논문을 읽고 그 결과와 관련된 실험 또는 재현실험을 하다보니 아주 작은 오류도 쉽게 드러나기 때문인 것으로 판단된다. 이 결과가 시사하 는 한 가지는 학술지의 진실성 가치를 높이는 데는 보 다 많은 독자를 갖는 것, 즉, reader의 영역을 국제화 하는 것이 매우 좋은 방법이라는 것이다. 또, 이를 뒤집 어서 생각하면, 학술지가 국제화되면 거기에 실린 논문 의 부실함이 쉽게 노출될 수 있다는 말도 가능하겠다.

\section{논문의 철회와 판정과 요청에 관한 한 사례}

논문의 철회는 누가 판정하고, 요청하는가? 저자가 하는가? 편집자가 하는가? 아니면, 기관이 하는가? 국 내 학술지(계)에서도 철회는 적지 않은 고민을 동반하 는 문제이지만, 이 질문에 대해서는 오랜 학술지 역사 를 갖고 있는 과학선진국에서도 고민과 갈등이 많은 것 같다.

지난해 10월 Nature지에서 다룬 한 가지 사례(case) 를 소개한다.[4] 1990년대 후반까지도 영국에서는 사 망한 어린아이들의 장기나 조직 샘플들을 병리학자들 이 부모의 동의 없이 적출하는 것이 관례였다고 한다. 리버플의 한 병원에서 근무하던 Dick van Velzen이라 는 병리학자는 빈번히 검시한 사체에서 장기를 추출하 고 이를 보관하였다가 후에 연구에 사용하였는데, 이러 한 행태가 결국 노출되었다. Redfern이라는 변호사가 주도한 정부조사위원회의 조사결과, Velzen은 검시도 제대로 하지 않은 채 사망진단서를 엉터리로 조작하여 제출했다고 한다. 그는 제대로 검시를 하지도 않고 적 
출한 조직을 가지고 영아사망원인에 대한 연구를 몇몇 학자들과 공동으로 하였고 적지 않은 수의 논문을 발표 하였는데, 그중 10 편의 논문에서는 조사대상이 된 아동 들은 물론 대조구 아동의 사망원인도 제대로 판별되지 않았기 때문에 Redfern은 이들 논문이 완전히 잘못된 것이라고 판정하였다. 이 조사의 결과로 Velzen은 영 국에서의 의술활동이 정지되었고, 그의 행적은 더 이상 찾을 수 없었다. 그런데, 2009년에 Holscher라는 신 경학자가 Velzen의 논문들에 관심을 갖고 뒤져보니 놀 랍게도 그 10 편의 논문 중 철회조치된 것은 한 편도 없 었다. Holscher는 이 논문들이 게재된 저널의 편집인 들에게 편지를 보내 "It's not okay that these papers are still in the public domain”이라고 하면 서 왜 이들이 철회되지 않았는지를 물었다. 그 결과 한 곳의 저널은 편지를 받은 즉시 논문을 철회하였으나, 나머지 논문들은 그렇게 되질 않았다. 편집인 중의 한 사람은 철회의 필요성을 느끼지 않는다고 답했다. 그는 논문의 "무효여부를 결정하는 것은 편집인의 일이 아 니다. (It is not up to me to judge whether the paper is invalid.)" 그리고, "편집인의 의무는 법적 문 제와는 관계가 없다(The editor's job does not have to do with judicial matters.)"라고 하였다. 이런 가 운데, 이 논문들은 지금도 읽히고 있는데, 이들 중 한 편은 2010년 이후에도 여섯 차례나 인용되었다고 한다.

한편, Velzen의 공동연구자들 중 한 명인 Vyvyan Howard는 자신들의 논문이 여전히 유효하다고 생각 하기 때문에 철회하지 않기로 했다고 한다. 그는 이 논 문들에는 Velzen의 잘못된 샘플의 문제가 개입되지 않 았는데, 이를 Redfern이 잘못 이해한 것이라고 주장하 면서, 자신들의 논문이 현재 의학시술방법의 개선에 공
헌한 바도 있다는 말까지 했다. 그러나, Redfern은 자 신의 조사가 잘못된 점이 없고, 지난 11 년 동안 한 번도 문제가 제기된 바가 없다고 하면서도, Howard의 주장 에 대해서는 언급을 피하였다. 한편, Holscher는 Redfern의 보고서는 매우 자세하고 신중하게 만들어 졌다고 하면서, Velzen이 소속되었던 리버풀 대학이 이 문제를 저자들에게 떠넘기지 말고 대학이 논문들의 철회를 요청했었어야 한다고 주장했다. 리버풀대학은 Redfern 보고서가 발표된 이후 Velzen의 샘플을 이용 한 모든 연구의 발표를 금지시켰으며, 현재 문제의 논 문들의 정당성에 대해서 조사하고 있고, 그 결과에 따 라서 철회여부를 결정할 것이라고 하였다. 그러나, 공 동연구자인 Howard가 속한 얼스터대학(University of Ulster)의 온라인출판 $\mathrm{DB}$ 에는 3 편의 논문이 여전히 공개되어 있고, 이 대학의 부총장은 이 논문들은 대학 의 교원이 연구를 통해 생산한 정당한 산물이라고 공언 하였다.

\section{논문의 철회여부를 판정할 때}

이 사례는 비록 명확해 보이는 case일지라도 많은 이해 당사자가 개입되면서 해석과 주장이 크게 달라질 수 있음을 잘 보여준다. 과학 학술지의 선진국인 영국 에서도 이럴진대, 인간관계와 체면을 중시하는 우리의 상황에서 학술지 편집인과 대학당국의 올바른 처신과 사안의 처리가 그리 용이하지는 않을 것이다. 그러나, 연구와 논문의 진실성을 밝히는 일은 세금을 납부하여 자신의 연구를 가능케 하는 국민, 나아가서 전 세계의 일반인 대중 모두에게 우리 과학자들이 실천해 보여야 할 가장 기본적인 의무가 아닐까 한다. 특히, 논문의 부 
정여부와 철회를 판정하는 데 있어서, 우리 편집인들은 지금보다는 조금 더 적극적인 자세를 가질 필요가 있 다. 논문의 과학적 진위여부를 가리는 일은 대학이나 다른 이해 당사자들이 하는 것보다 학술지 중심으로 전 문가들이 모여 직접 판단하는 것이 보다 공정하고 정확 할 것이기 때문이다. 또한, 편집인이 논문의 철회여부 를 판정할 때, 그 논문 자체 외에 여러 이해 당사자들의 입장과 의견을 고려하는 신중함은 그리 필요한 미덕은 아닐 것이다. 이러한 배려는 오히려 종종 연구의 진실 성이 인간관계에 밀려 무시되는 결과를 야기하기 때문 이다. 한 가지 더 우리 편집인들이 신경을 써야 할 일이 있다. Steen에 의하면, 철회된 논문의 31.8 퍼센트가 독자들에게 제대로 알려지지 않고 있다고 한다.[2] 철 회된 논문임을 독자가 알지 못한다면, 그 논문을 철회 한 가장 중요한 목적이 달성될 수 있겠는가? 검색 사이 트에 '게재철회(retraction)' 표시를 하고, 웹에서 접 근할 수 있는 논문의 $\mathrm{PDF}$ 파일을 삭제하는 등을 실행 하는 노력이 절실하다.

\section{참고문헌}

${ }^{1}$ Fanelli D. How many scientists fabricate and falsify research? A systematic review and meta-analysis of survey data. PLoS One 4, e5738 (2009).

2 Steen RG. Retractions in the scientific literature: Is the incidence of research fraud increasing? J. Med. Ethics 37, 249-253 (2011).

3 Fang FC, Casadevall A. Retracted science and the retraction index. Infect. Immun. 79, 38553859 (2011).

4 Marchant J. 'Flawed' infant death papers not retracted. Nature 476, 263-264 (2011). 0 